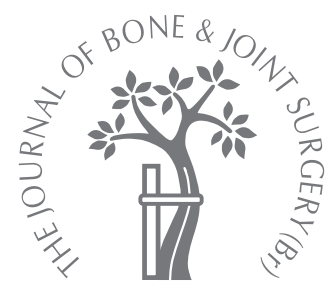

\title{
The incidence and treatment of rocker bottom deformity as a complication of the conservative treatment of idiopathic congenital clubfoot
}
G. Koureas,
V. Rampal,
E. Mascard,
R. Seringe,
P. Wicart

From Université René

Descartes, Paris,

France
G. Koureas, MD, PhD, Orthopaedic Surgeon Kokkinou 12-14 \& Zaimi st, TK 27100, Pyrgos, Ilias, Greece.

V. Rampal, MD, Fellow E. Mascard, MD, Orthopaedic Surgeon

R. Seringe, MD, Professor, Head of Department P. Wicart, MD, PhD, Professor Department of Paediatric Surgery

Saint-Vincent-de-Paul Hospital (APHP), 74-82 avenue DenfertRochereau, 75674 Paris Cedex 14, France.

Correspondence should be sent to Professor P. Wicart; e-mail: p.wicart@svp.aphp.fr

(C)2008 British Editorial Society of Bone and Joint Surgery doi:10.1302/0301-620X.90B1. $19329 \$ 2.00$

$J$ Bone Joint Surg $[\mathrm{Br}]$ 2008;90-B:57-60.

Received 19 February 2007; Accepted after revision 20

September 2007

\begin{abstract}
Rocker bottom deformity may occur during the conservative treatment of idiopathic congenital clubfoot. Between 1975 and 1996, we treated 715 patients (1120 clubfeet) conservatively. A total of 23 patients (36 feet; $3.2 \%$ ) developed a rocker bottom deformity. It is these patients that we have studied. The pathoanatomy of the rocker bottom deformity is characterised by a plantar convexity appearing between three and six months of age with the hindfoot equinus position remaining constant. The convexity initially involves the medial column, radiologically identified by the talo-first metatarsal angle and secondly by the lateral column, revealed radiologically as the calcaneo-fifth metatarsal angle. The apex of the deformity is usually at the midtrasal with a dorsal calcaneocuboid subluxation. Ideal management of clubfoot deformity should avoid this complication, with adequate manipulation and splinting and early Achilles' percutaneous tenotomy if plantar convexity occurs.

Adequate soft-tissue release provides satisfactory correction for rocker bottom deformity. However, this deformity requires more extensive and complex procedures than the standard surgical treatment of clubfoot. The need for lateral radiographs to ensure that the rocker bottom deformity is recognised early, is demonstrated.
\end{abstract}

The incidence of idiopathic congenital clubfoot varies between 0.6 and 1 per 1000 births. ${ }^{1-3}$ The initial treatment is usually conservative. ${ }^{4-11}$ Rocker bottom deformity of the foot may be a complication of this conservative treatment. It comprises dorsiflexion of the forefoot without correction of hindfoot equinus, resulting in a plantar convexity with false sagittal correction. It must be distinguished from congenital vertical talus. Their pathophysiology is radically different but their appearance may be similar. Careful examination of the case history allows the conditions to be differentiated from one another. Despite several reports of this complication, ${ }^{6,12,13}$ it has not been the subject of a detailed analysis.

Our aim was to describe the pathoanatomy of the rocker bottom foot deformity, to analyse its occurrence during conservative treatment of clubfoot in order to identify early diagnostic indicators and to propose preventative measures and forms of corrective treatment.

\section{Patients and Methods}

We reviewed 715 patients (1120 feet) who had been conservatively treated ${ }^{8}$ for a clubfoot deformity between 1975 and 1996 at St. Vincent de Paul Hospital, Paris. Of these, 23 patients (36 feet; 3.2\%) developed a rocker bottom deformity (Fig. 1) and were further analysed.

Standard conservative treatment for clubfoot deformity. All feet were initially treated by manipulation, muscular stimulation of the dorsolateral aspect of the foot, and fixation of the foot on a rigid plastic plate fixed to the plantar aspect of the foot with a non-elastic strapping, followed by immobilisation in an above-knee splint, with the knee in $90^{\circ}$ flexion and the ankle in a neutral position, until six months of age. ${ }^{8}$ Between the age of six months and one year, the patients had a below-knee posterior splint applied during the day, and an above-knee posterior splint during the night. Once walking age was reached, an above-knee splint was used only during the night.

Methods of evaluation. The severity of the foot deformity at birth was evaluated using the Dimeglio score ${ }^{14}$ first published in 1995. For most patients, this score has been applied retrospectively, using photographs taken prior to commencing any treatment showing the extent of the deformity in the three anatomical planes, and with the assistance of a trained physiotherapist. 


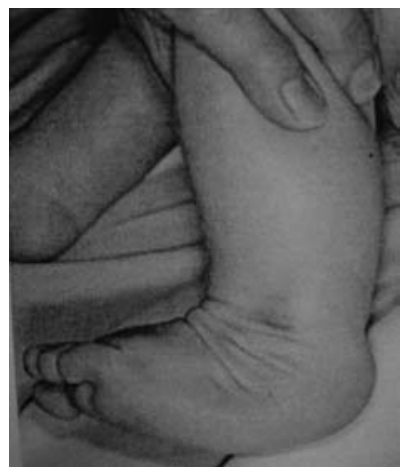

Fig. 1a

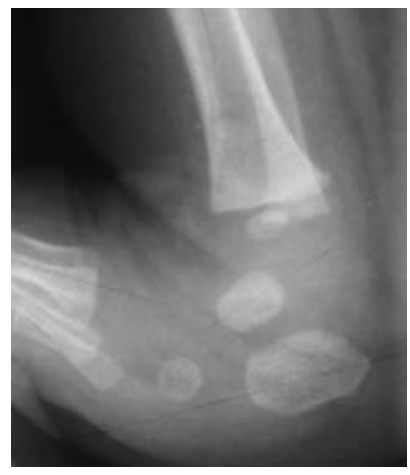

Fig. 1b a) Clinical and b) radiological appearance of rocker bottom foot deformity.

The final result was assessed using the Ghanem and Seringe score ${ }^{15}$ which has 100 points available. As rocker bottom deformity is a sagittal deformity the results have focused on the sagittal plane. Dorsiflexion of the foot relative to the leg was estimated. Lateral radiographs were evaluated at the onset of treatment, and at one, four and six months of age with the foot held with maximum correction. Once the child was walking, radiographs were obtained in the standing position. Radiological measurements included the tibiocalcaneal, calcaneo-fifth metatarsal and talo-first metatarsal angles (Fig. 2a). Dorsal calcaneocuboid subluxation was quantified as a percentage of the vertical displacement of the cuboid relative to its height (Fig. 2b).

Intra- and interobserver reliability was examined by repeating the measurements after a three-week interval. For the first observer, the intra-observer assessment was $r=-0.81$ and for the second, $r=0.79$. The interobserver reliability was also good with $\mathrm{r}=0.76$ and $\mathrm{r}=0.77$ for the two observers respectively.

Statistical analysis. Student's $t$-test was used for the comparison of differences between the angles measured. Statistical significance was set at $\mathrm{p}<0.05$. The correlation coefficient was used to evaluate the relationship between dorsal calcaneocuboid subluxation and plantar convexity.

\section{Results}

The mean follow-up period was 15.4 years (5 to 30 ), during which time 30 feet had reached skeletal maturity defined as more than 14 years of age for girls and 16 years for boys.

Characterisation of rocker bottom deformity. At first examination, $67 \%$ of the feet $(24)$ were in the most severe Dimeglio categories (Dimeglio C, 11\% (four feet) and Dimeglio D, $56 \%$ (20 feet)). There were no feet in the less severe groups (Dimeglio A and B). The remaining 33\% (12 feet) could not be classified because of a lack of clinical information necessary for the retrospective analysis.

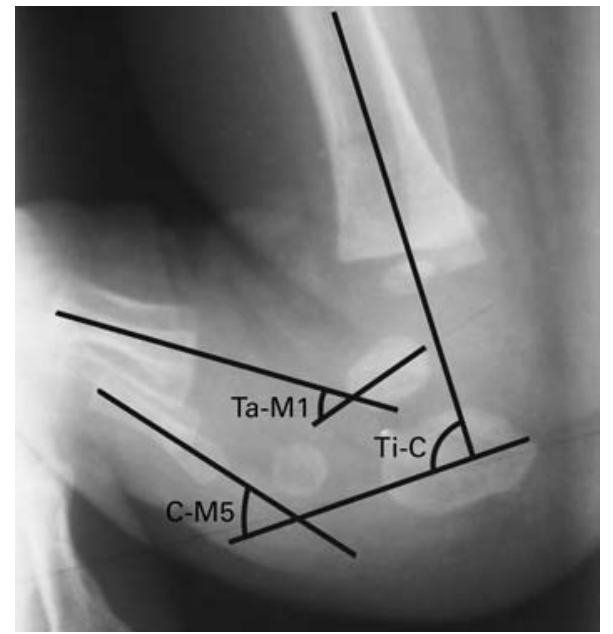

Fig. 2a

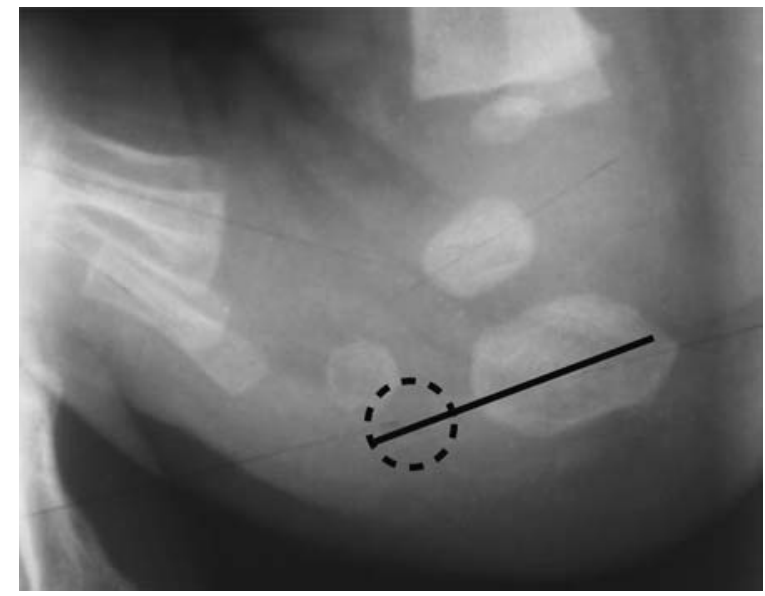

Fig. 2b

Lateral radiographs showing a) the measurement of the tibiocalcaneal (Ti-C), calcaneo-fifth metatarsal (C-M5), and talo-first metatarsal (Ta-M1) angles and b) the percentage of calcaneocuboid subluxation. In this example it is $95 \%$.

Evaluation of the diagnostic criteria and progression before surgical intervention was undertaken for the whole series. Dorsiflexion improved from a mean of $-2.1^{\circ}$ (SD 15.7) at birth to $6.4^{\circ}$ (SD 16.8) during the three- to sixmonth follow-up period $(\mathrm{p}=0.006)$. In contrast, the mean hindfoot equinus, as measured radiologically by the tibiocalcaneal angle, did not change significantly during the same period $(\mathrm{p}=0.27$; Table I). The difference between the clinical estimation of dorsiflexion and the radiologicallymeasured hindfoot equinus cannot adequately be explained. Further analysis showed that the mean calcaneo-fifth metatarsal angle also did not change significantly during the first six months after birth $(\mathrm{p}=0.20)$. However, the talo-first metatarsal angle developed an 
Table I. Mean (SD) radiological results from birth to final follow-up

\begin{tabular}{|c|c|c|c|c|c|}
\hline & Dorsiflexion ( ${ }^{\circ}$ ) & $\begin{array}{l}\text { Tibiocalcaneal } \\
\left.\text { angle ( }{ }^{\circ}\right)\end{array}$ & $\begin{array}{l}\text { Talo-first metatarsal } \\
\text { angle }\left({ }^{\circ}\right)\end{array}$ & $\begin{array}{l}\text { Calcaneo-fifth metatarsal } \\
\text { angle }\left({ }^{\circ}\right)\end{array}$ & $\begin{array}{l}\text { Calcaneocuboid } \\
\text { subluxation (\%) }\end{array}$ \\
\hline 1 to 2 months old ( 36 feet) & $-2.1(15.7)$ & $87.2(10.7)$ & $-32(16.2)$ & $-30.2(17.1)$ & - \\
\hline 3 to 6 months old ( 36 feet) & $6.4(16.8)$ & $87.0(12.9)$ & $-38.6(20.9)$ & $-31.8(15.2)$ & $43.5(26.3)$ \\
\hline Pre-operative (36 feet) & $2.1(15.2)$ & $95.4(12.9)$ & $-33.2(18.5)$ & $-31.4(15.6)$ & $45.0(21.7)$ \\
\hline Skeletal maturity (30 feet) & $7.6(7.8)$ & $89.5(4.7)$ & $-1.4(7.1)$ & $1.0(5.3)$ & 0.0 \\
\hline
\end{tabular}

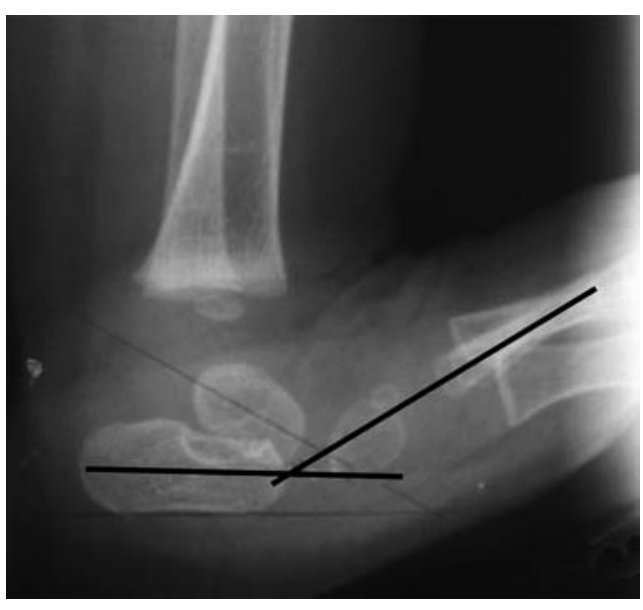

Fig. 3a

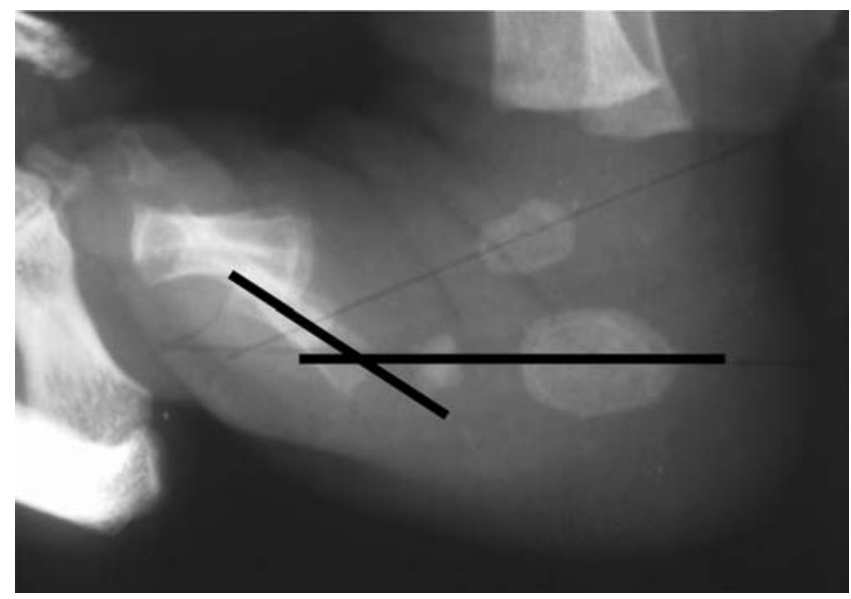

Fig. 3b

Lateral radiographs of a) a patient with a plantar convexity in the Chopart joint. The long axis of the calcaneum passes beneath the cuboid while the long axis of the fifth metatarsal passes through it, and b) a patient with the apex of a plantar convexity in the Lisfranc joint. The long axis of the calcaneum passes through the centre of the cuboid. In contrast, the long axis of the fifth metatarsal passes beneath the cuboid.

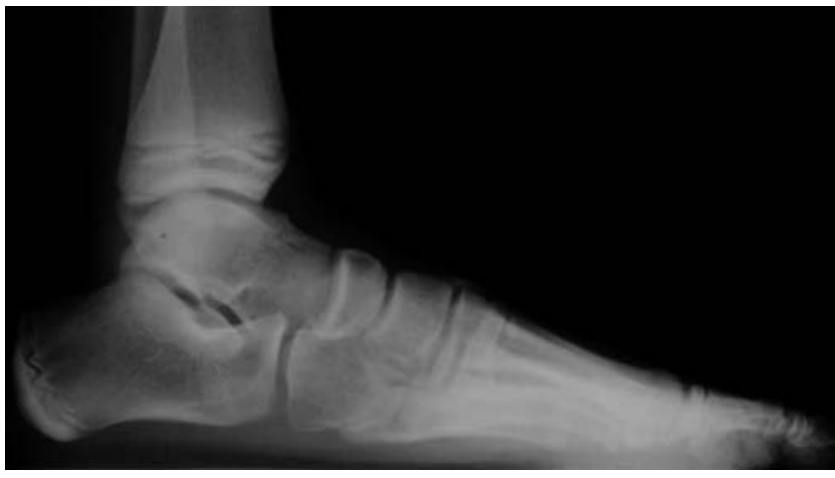

Fig. 4

Radiograph of the same patient as in Figure 3a, showing a satisfactory result at final follow-up of 14 years.

increase in convexity. Its mean value at one to two months of age was $-32^{\circ}$ (SD 16.2) while at three to six months it was $-38.6^{\circ}$ (SD 20.9) ( $\left.\mathrm{p}=0.003\right)$. At that time a significant difference between the convexity of a foot's medial and lateral rays was observed as demonstrated by the mean talofirst metatarsal and mean talo-fifth metatarsal angles ( $t$-test, $\mathrm{p}=0.028$ ), suggesting that the medial ray convexity was increasing earlier than the lateral side. The peak of calcaneocuboid dorsal subluxation was observed during the three- to six-month interval and the pre-operative period (Table I). There was a correlation between the mean talofirst metatarsal angle and mean dorsal calcaneocuboidal subluxation $(\mathrm{r}=-0.71)$ during the three- to six-month interval. This implies that the more the cuboid was subluxed dorsally, the greater the plantar convexity. The apex of the deformity was the midtarsal joint in 34 feet (Fig. 3a). Only two feet developed a convexity located in the tarsometatarsal joint (Fig. 3b).

Treatment of rocker bottom deformity. If a rocker bottom deformity was observed during the follow-up, an aboveknee plaster cast with equinus and plantar cavus was applied for one month, attempting to correct the plantar convexity and the calcaneocuboid subluxation. This method was successful in three feet $(8.3 \%)$.

The remaining $33(91.7 \%)$ required surgical correction. Their mean age at surgery was 12 months (5 months to 3.2 years). Correction of the hindfoot equinus was accomplished in all cases with a posterolateral release including lengthening of tendo Achillis, posterior ankle capsulotomy, and posterolateral release. In nine feet, this release allowed 
restoration of the normal plantar concavity as well. However, after correction of hindfoot equinus, plantar convexity and adduction deformity persisted in 24 feet $(67 \%)$. This residual deformity required a dorsomedial talonavicular release combined with anterior and posterior lengthening of the tibialis tendons. The talonavicular joint was repositioned and stabilised with a Kirschner (K-) wire for nine months.

A calcaneocuboid dorsal subluxation persisted in 14 feet $(38.8 \%)$. Correction was achieved with different procedures including reduction of calcaneocuboid dorsal subluxation with percutaneous or open pinning of the lateral ray, dorsolateral calcaneocuboid capsulotomy and/or distal intra-articular calcaneal resection. ${ }^{16}$

The final results were studied in the 30 patients who reached skeletal maturity. The final Ghanem and Seringe score $^{15}$ was excellent in 47\% (14 feet) (Fig. 4), good in 23\% (seven feet), fair in $23 \%$ (seven feet) and poor in $7 \%$ (two feet). The correction of the characteristics of the rocker bottom deformity are shown in Table I.

\section{Discussion}

When a rocker bottom deformity occurs as a complication of the conservative treatment of clubfoot it is likely to become apparent between three and six months of age. The apex of the convexity is almost always located in the midtarsal joint. The radiologically identified calcaneocuboid dorsal subluxation observed at six months represents a relatively late, but almost constant, element of diagnosis.

In our hospital, the incidence of this complication was $3.2 \%$. It has been previously described as a complication of various forms of treatment, ${ }^{6,12,13}$ depending more on the severity of the clubfoot deformity than on the treatment itself. Clinical examination can be misleading as an increase in the forefoot dorsiflexion can be mistakenly interpreted as an improvement of the foot and ankle alignment if the residual hindfoot equinus is not appreciated. In this situation palpation of the high position of the calcaneum in the heel pad is not always reliable, particularly in young children. Therefore, it is essential to examine the lateral radiograph in order to diagnose a rocker bottom deformity.

The fact that the majority of these deformities occurred in feet which had severe clubfoot deformity at birth suggests that stiff joints and particularly equinus might contribute to its occurrence.

In order to prevent this complication, forcible manipulation of the distal and midparts of the foot is contraindicated. The resistance of the soft-tissues of the midfoot should not be overestimated. Traction on the calcaneum itself is preferred to correct equinus. Strapping of the foot in a concave rigid sole during the initial treatment is important in order to respect the sagittal architecture of the foot. Gray and $\mathrm{Katz}^{17}$ and Radler et $\mathrm{al}^{18}$ have reported that an early percutaneous tenotomy of tendo Achillis may prevent rocker bottom deformity. This is also proposed in the Ponseti treatment. ${ }^{11}$

When a rocker bottom deformity becomes apparent, a below-knee plaster cast, with equinus and plantar cavus for one month may be sufficient to correct the deformity but had limited success in our series. Most of our patients with rocker bottom deformity required surgical treatment, although this varied from isolated soft-tissue release to osseous procedures to obtain satisfactory correction. However, a rocker bottom deformity is often combined with a three-dimensional deformity, requiring more extensive and complex procedures. In conclusion, the ideal treatment of rocker bottom deformity is an early radiological diagnosis and prevention with percutaneous Achilles tendon tenotomy.

No benefits in any form have been received or will be received from a commercial party related directly or indirectly to the subject of this article.

\section{References}

1. Carey M, Bower C, Mylvaganan A, Rouse I. Talipes equinovarus in Western Australia Paediatr Perinat Epidemiol 2003;17:1987-94.

2. Moorthi RN, Hashmiss SSW, Langlois $\mathbf{P}$, et al. Idiopathic talipes equinovarus (ITEV) (clubfeet). Am J Med Genet A 2005;132:376-80.

3. Ventura SJ, Martin JA, Curtin SC, Mathews TJ. Report of final natality statistics, 1996. Mon Vital Stat Rep 1998;46(Suppl):1-99.

4. Reimann I, Lyquist E. Dynamic splint used in the treatment of club foot. Acta Orthop Scand 1969;40:817-24.

5. Shaw NE. The early management of clubfoot. Clin Orthop 1972;84:39-43.

6. Kite JH. Nonoperative treatment of congenital clubfoot. Clin Orthop 1972;84:29-38.

7. Harrold AJ, Walker CJ. Treatment and prognosis in congenital club foot. J Bone Joint Surg [Br] 1983;65-B:8-11.

8. Seringe R, Atia R. Idiopathic congenital club foot: results of functional treatment (269 feet). Rev Chir Orthop Reparatrice Appar Mot 1990;76:490-501 (in French).

9. Diméglio A, Bonnet F, Mazeau P, De Rosa V. Orthopaedic treatment and passive motion machine: consequences for the surgical treatment of clubfoot. J Pediatr Orthop B 1996:5:173-80.

10. Morcuende JA, Dolan LA, Dietz FR, Ponseti IV. Radical reduction in the rate of extensive corrective surgery for clubfoot using the Ponseti method. Pediatrics 2004;113:376-80.

11. Ponseti IV, Zhinkov M, Davis N, et al. Treatment of the complex idiopathic clubfoot. Clin Orthop 2006;45:171-6.

12. Ponseti IV. Congenital clubfoot. In: Fundamentals, of treatment. Oxford: Oxford Medical Publications, 1996:133-80.

13. Crawford AH, Gupta AK. Clubfoot controversies: complications and causes for failure. Instr Course Lect 1996;45:339-46.

14. Dimeglio A, Bensahel H, Souchet P, Mazeau P, Bonnet F. Classification of clubfoot. J Pediatr Orthop B 1995;4:129-36.

15. Wicart PR, Barthes $X$, Ghanem I, Seringe R. Clubfoot posteromedial release: advantages of tibialis anterior tendon lengthening. J Pediatr Orthop 2002;22:526-32.

16. Lichtblau S. A medial and lateral release operation for clubfoot: a preliminary report. $J$ Bone Joint Surg [Am]1973;55-A:1377-84.

17. Gray DH, Katz JM. A histochemical study of muscle in club foot. J Bone Joint Surg [Br] 1981;63-B:417-23.

18. Radler C, Manner HM, Suda R, et al. Radiographic evaluation of idiopathic clubfeet undergoing Ponseti treatment. J Bone Joint Surg [Am]2007;89-A:1177-83. 